\title{
Ozone and carbon monoxide over India during the summer monsoon: regional emissions and transport
}

Narendra Ojha et al.

Correspondence to: Narendra Ojha (narendra.ojha@mpic.de)

The copyright of individual parts of the supplement might differ from the CC-BY 3.0 licence. 

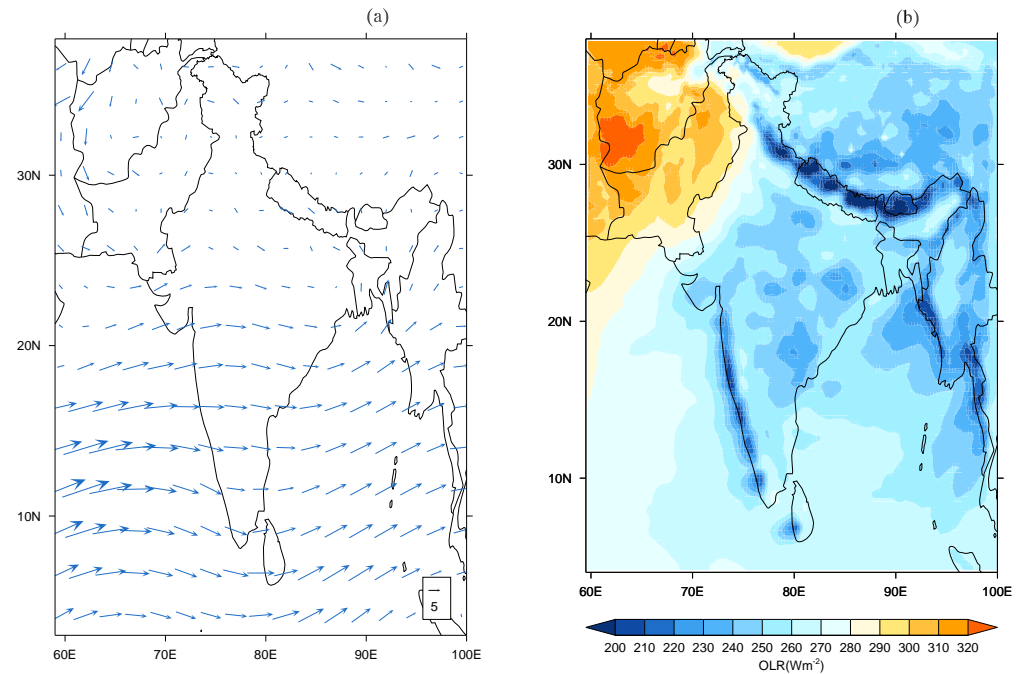

Figure 1: WRF-Chem simulated average wind-pattern at $850 \mathrm{hPa}$ and Outgoing Longwave Radiation (OLR) during July 2008 over Indian region 


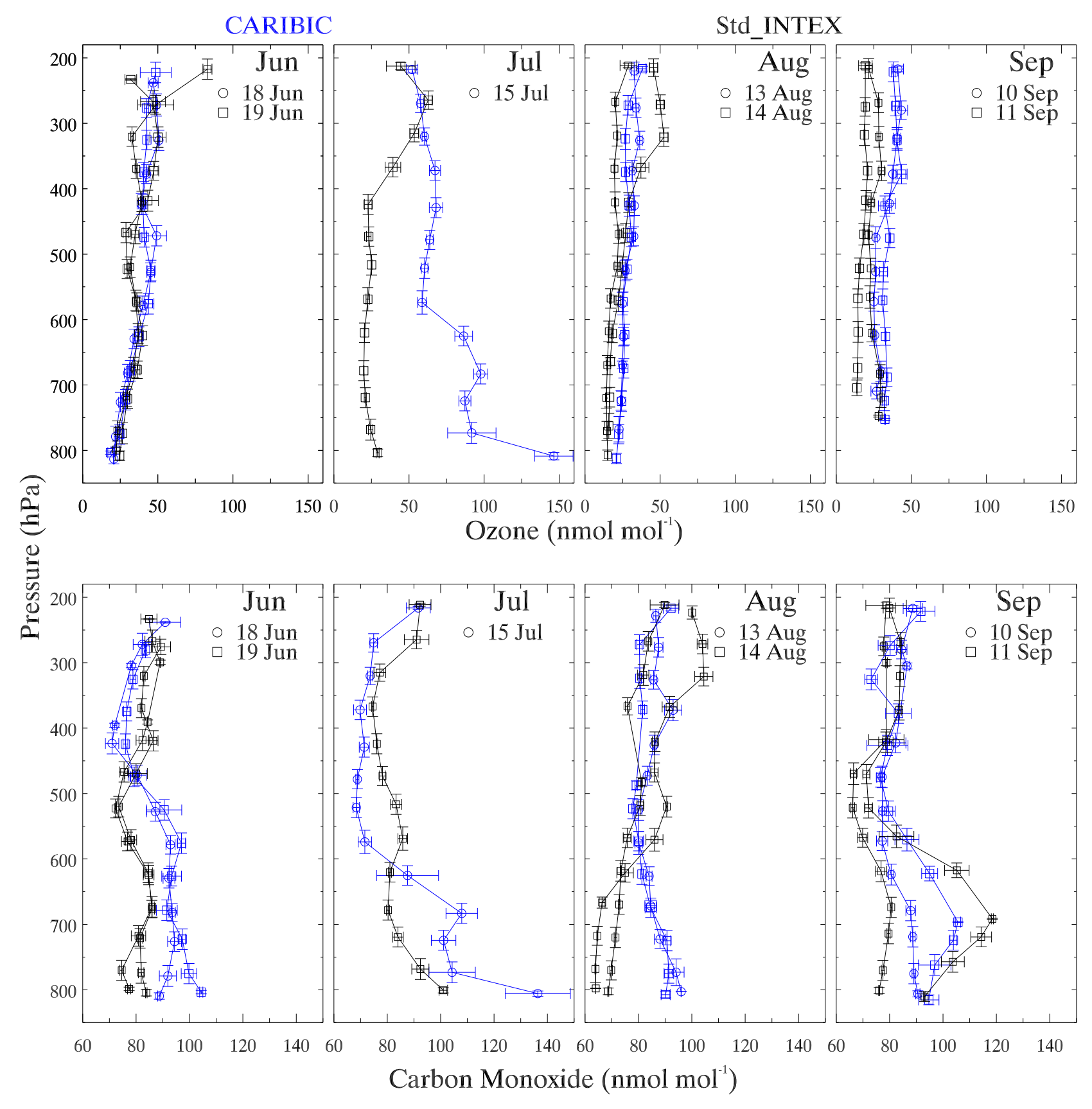

Figure 2: Comparison of ozone and carbon monoxide profiles from CARIBIC observations with WRF-Chem simulations driven by INTEX-B emission inventory. 


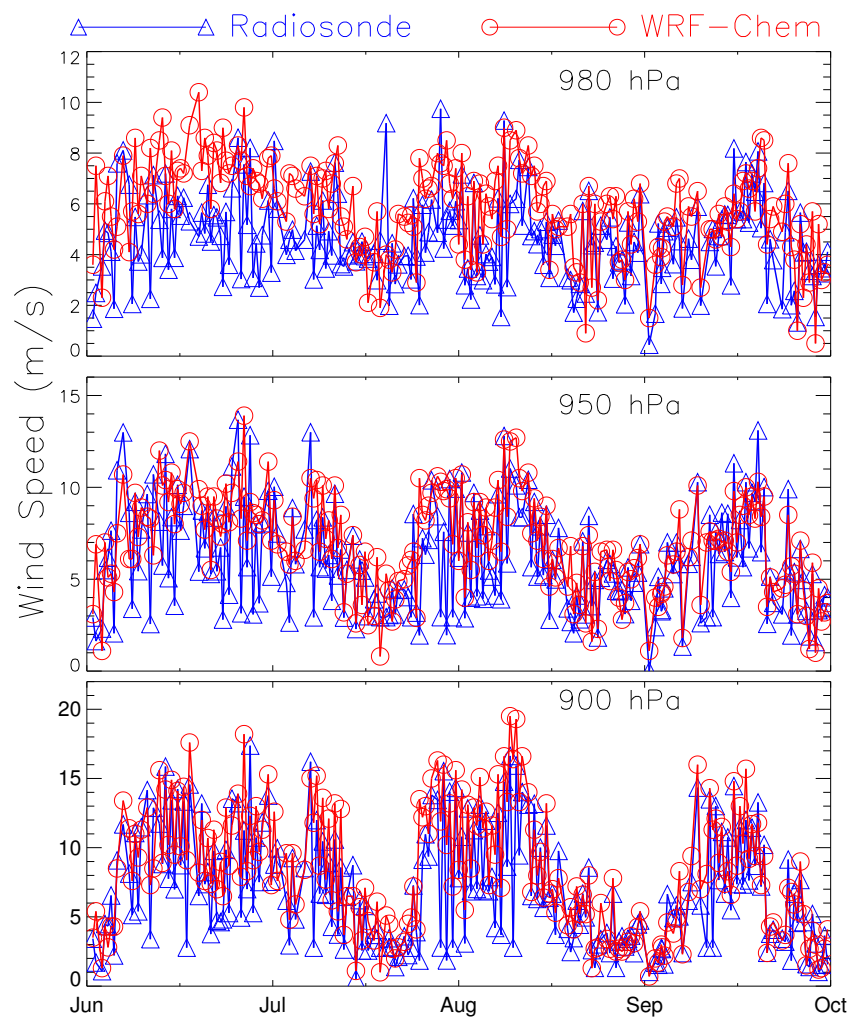

Figure 3: Comparison of WRF-Chem (std) simulated wind speed with radiosonde observations over Chennai.

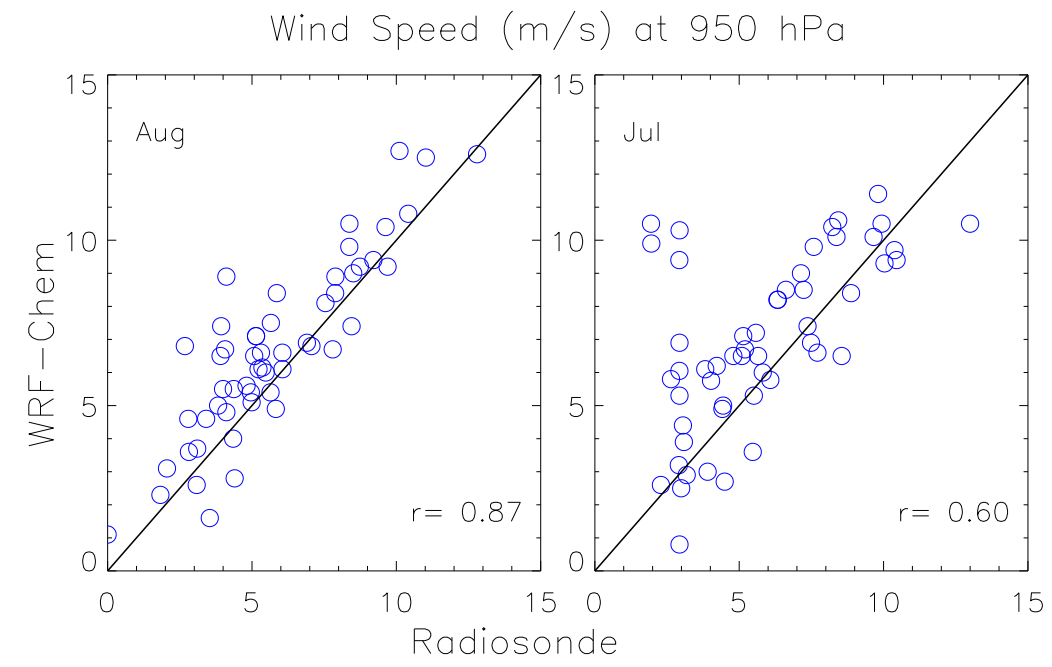

Figure 4: Scatter plot of wind speed $(\mathrm{m} / \mathrm{s})$ between WRF-Chem (std) simulations and radiosonde observations over Chennai. 


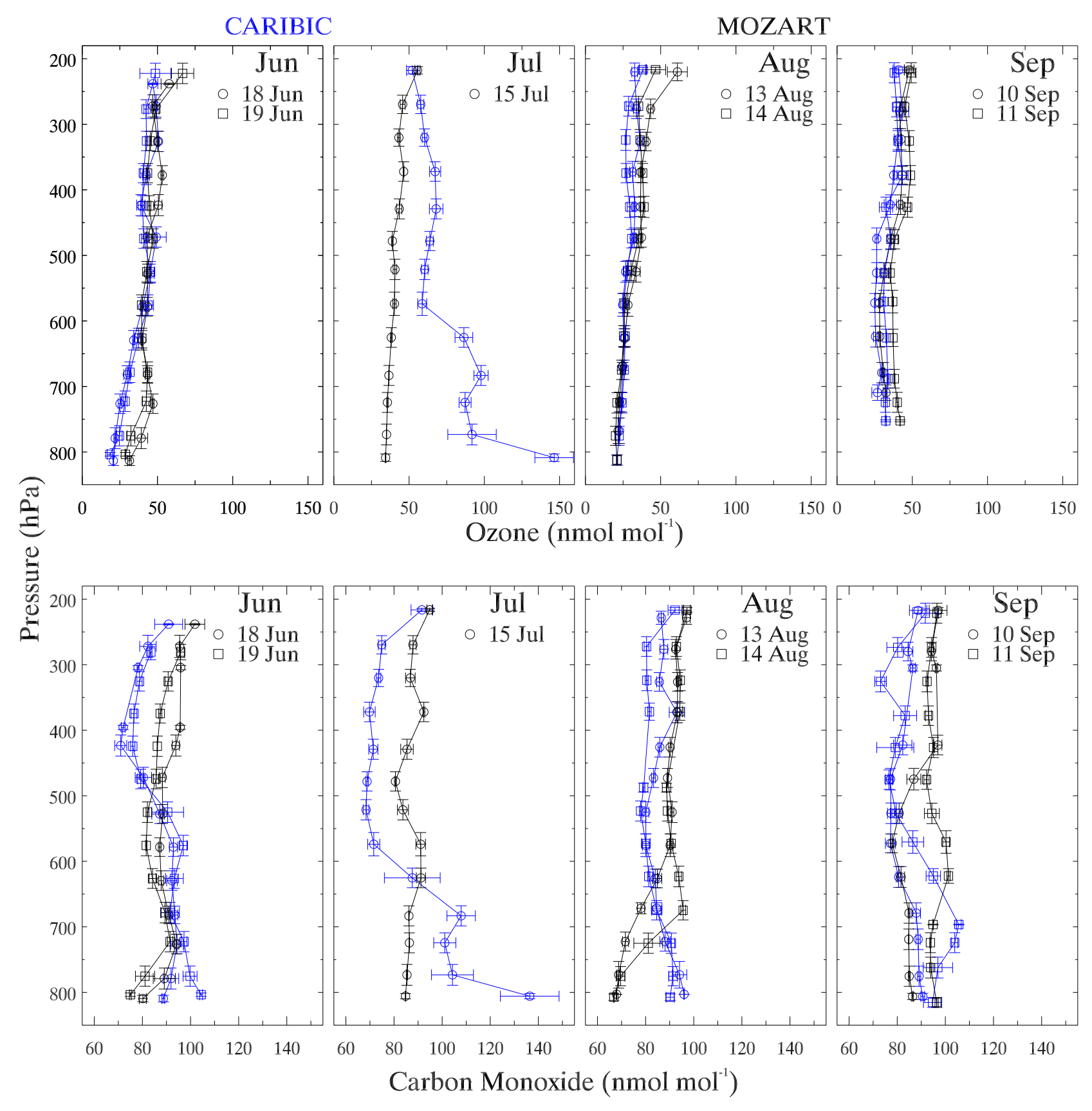

Figure 5: Comparison of ozone and carbon monoxide profiles from CARIBIC observations with MOZART/GEOS5 data during June, July, August and September 2008. MOZART data has been interpolated along the CARIBIC flight tracks. Only data collected during the aircraft descent is shown here. 